\title{
Pattern And Distribution of Injuries in Fatal Road Traffic Accident Cases
}

\author{
Dr.RajivRanjan ,Dr.Dharmendra kumar,Dr. SandeepprasadLal \\ ${ }^{I}$ Tutor Dept Forensic Medicine \&Toxicology ,J.L.N.M.C.H,Bhagalpur. \\ ${ }^{2}$ Senior Resident.Dept Of E.N.T J.L.N.M.C.H Bhagalpur, \\ ${ }^{3}$ Associate Professor, Dept Forensic Medicine \&Toxicology J.L.N.M.C.H Bhagalpur
}

\begin{abstract}
Objective:Road traffic injuries are one of the leading causes of death in the world. The present study aims at evaluation of pattern and distribution of injuries among road traffic accident thereby planning successful measures to minimize fatalities

Methods: Our study done at dept of F.M.T at J.L.N.M.CH Bhagalpur from March 2015 and March 2016. This study included 500 cases of road traffic accident victims of fatal road traffic accident, brought for medico-legal postmortem examination.

Results:Highest number (33\%) of fatalities occurred in the 25-44 years age group followed by the age group 15-25 years (23\%). Male victims outnumbered female resulting in male to female ratio of 1.8:1.Pedestrians were most vulnerable accounting for $36 \%$ of total fatalities followed by motorized two wheelers $31 \%$. Heavy Vehicles were found to be mostly involved $56.02 \%$ of cases and most accidents $83.15 \%$ occurred on highways. Majority of cases sustained multiple injuries.. Largest number of injuries were recorded in head \& neck 425 number, followed by lower extremities325 number. Vehicle occupants mostly sustained thoracic injuries. In majority of cases, the site of initial impact of the responsible vehicle was frontal followed by rear and side. .
\end{abstract}

Keyword:Accidents, Head Injury

\section{Introduction}

Among all traffic accident, road traffic accidents claim largest toll of human life and tend to be the most serious problem world over. During 1990s road traffic accident injuries ranked ninth among the leading causes of deaths in world. It is projected to become second leading cause by the year 2020 next to ischemic heart disease. About 3.5 million people die of unintentional injuries. Road traffic accidents claim 1.2 million lives. The Americas bear $11 \%$ of the burden of road traffic injury mortality. Nearly three quarter of death resulting from motor vechicle crashes occur in developing country. In india over 80000 person die in traffic crashes annually, over 1.2 million injured seriously and about 3,00,000 disabled permanently. In India, for individuals morethan 4 years of age, more life years are lost due to traffic crashes than due to cardiovascular diseases or neoplasm. The problem appears to beincreasing rapidly in developing countries. The present study was conducted on 500 autopsy cases to ascertain incidence of fatal road traffic accidents and to find pattern and distribution of injuries.

\section{Material \& method}

This study included 500 cases of fatal road traffic accidents brought to J.L.N.M.C Bhagalpur,for medico-legal postmortem examination, details of which had been recorded. The cases were brought directly from the site of accident or who died after admission following road traffic accidents. The relevant information was collected from:

- The inquest report and other relevant papers brought by the police

- Interviewing the police personnel accompanying the dead

- Interviewing the relatives, neighbors, friends, or persons accompanying the deceased.

- The data thus collected was analyzed statistically.

\section{Result}

In present study 500 autopsies of road traffic accident victim were conducted in the department of Forensic Medicine \&Toxicology J.L.N.M.C Bhagalpur . All the observation noted and result , are as below:

\begin{tabular}{|c|c|c|c|c|c|c|c|c|}
\hline & Age & & \multicolumn{2}{|c|}{ Victims Cases } & & \multirow[t]{2}{*}{ Type of } & \multicolumn{2}{|c|}{ Cases } \\
\hline \multirow[t]{2}{*}{ S.No. } & group & & & & & & & \\
\hline & Vo & Male & Female & No. & $\%$ & $\begin{array}{l}\text { Road } \\
\text { Users }\end{array}$ & No. & $\%$ \\
\hline & & & & & & & & \\
\hline
\end{tabular}


Pattern And Distribution Of Injuries In Fatal Road Traffic Accident Cases

\begin{tabular}{|c|c|c|c|c|c|c|c|c|}
\hline 1 & $<10$ & 15 & 10 & 25 & 5 & Pedestrian & 180 & 36 \\
\hline 2 & $11-14$ & 35 & 20 & 55 & 11 & Motorized & 155 & 31 \\
\hline 3 & $15-24$ & 90 & 25 & 115 & 23 & 2-Wheeler & & \\
\hline \multirow[t]{2}{*}{4} & \multirow[t]{2}{*}{$25-44$} & \multirow[t]{2}{*}{110} & \multirow[t]{2}{*}{55} & \multirow[t]{2}{*}{165} & \multirow[t]{2}{*}{33} & Vehicle & \multirow[t]{2}{*}{110} & \multirow[t]{2}{*}{22} \\
\hline & & & & & & Occupants & & \\
\hline \multirow[t]{2}{*}{5} & \multirow[t]{2}{*}{$45-64$} & \multirow[t]{2}{*}{70} & \multirow[t]{2}{*}{30} & \multirow[t]{2}{*}{100} & \multirow[t]{2}{*}{20} & Pedal & \multirow[t]{2}{*}{30} & \multirow[t]{2}{*}{6} \\
\hline & & & & & & Cyclists & & \\
\hline \multirow[t]{3}{*}{6} & $65 \&$ & \multirow[t]{2}{*}{29} & \multirow[t]{2}{*}{11} & \multirow[t]{2}{*}{40} & \multirow[t]{2}{*}{8} & Others & 20 & 4 \\
\hline & Above & & & & & Unknown & 5 & 1 \\
\hline & Total & 349 & 151 & 500 & 100 & Total & 500 & 100 \\
\hline
\end{tabular}

In the present study, the age of the victims varied from 6 to 67 years. Highest number $(33 \%)$ of fatalities occurred in 25-44 years age group followed by the age group 15-25 years (23\%), 45-64 years(20\%) and $>65$ years $(8 \%), 11-20$ years $(11 \%)$, and $<10$ years $(5 \%)$. Nearly three-fourth of the victims were males $(69.8 \%)$ while the females constituted only $(31.2 \%)$ cases.

Tabel 3 Showing different type of vechiles involved in fatal RTA, sites of accident in relation to road and number vechiles involved :-

\begin{tabular}{|c|c|c|c|c|c|c|c|c|}
\hline Vehicle & \multicolumn{2}{|c|}{ Cases } & Types of & \multicolumn{2}{|c|}{ Cases } & Vehicle & \multicolumn{2}{|c|}{ Cases } \\
\hline Type & No. & $\%$ & Road & No. & $\%$ & Involved & No. & $\%$ \\
\hline $\begin{array}{l}\text { Heavy } \\
\text { Vehicle }\end{array}$ & & & Highways & 789 & 83.05 & $\begin{array}{l}\text { Single } \\
\text { Vehicle }\end{array}$ & 416 & 83.15 \\
\hline $\begin{array}{l}\text { a) Truck, } \\
\text { Oil Tanker }\end{array}$ & 201 & 40.02 & & & & & & \\
\hline b) Motor & 80 & 16 & & & & & & \\
\hline & & & & & & Double & 70 & 14.00 \\
\hline $\begin{array}{c}\text { Light } \\
\text {,Vehicles } \\
\text { Taxi, Car, } \\
\text { Jeep }\end{array}$ & 112 & 22.4 & Roads & 150 & 15.58 & & & \\
\hline Motorized & 75 & 15 & Lane & 6 & 0.63 & Triple & 2 & 0.4 \\
\hline 2-wheelers & & & & & & Vehicle & & \\
\hline $\begin{array}{c}\text { Other } \\
\text { Vehicles }\end{array}$ & 28 & 5.6 & $\begin{array}{l}\text { Other } \\
\text { Places }\end{array}$ & 2 & 0.21 & & & \\
\hline Unknown & 4 & 0.8 & Unknown & 5 & 0.53 & $\begin{array}{c}\text { Unknow } \\
n\end{array}$ & 12 & 2.4 \\
\hline Total & 500 & 100 & Total & 950 & 100 & Total & 500 & 100 \\
\hline
\end{tabular}

Tabel 4sites Of Injuries In Road Traffic Accidents

\begin{tabular}{|l|l|l|l|l|}
\hline & S. & & No. of & \\
\hline & No. & Site of injuries & cases & \%age \\
\hline & & & & \\
\hline & 1. & Head \& Face & 425 & 85 \\
\hline & 2. & Chest & 240 & 48 \\
\hline & 3. & Abdomen & 180 & 36 \\
\hline & 4. & Upper limbs & 270 & 54 \\
\hline & 5. & Lower limbs & 325 & 65 \\
\hline & 6. & Spine injury & 5 & 1 \\
\hline & & Total & 1400 & \\
\hline & & & & \\
\hline
\end{tabular}

Tabel3 show distribution of cases involved. Multiple body parts were involved in each cases. Injuries to head and face were observed in $85 \%$ of all injuries next common injuries were obsereved in lower limb in $65 \%$ victim and in upper limb in 54\%.Injuries to chest were seen in $48 \%$, to abdomen in $36 \%$ and spine and neck in $1 \%$ case. Total number of injuries seen in 500 victim 1400. 
Tabel 4 Distribution of cases according to type of injuries

\begin{tabular}{|l|l|l|l|c|}
\hline & S. & Type of Injury & No. & of \%age \\
\hline & No. & & cases & \\
\hline & & & & \\
\hline & 1. & Abrasions & 430 & 86 \\
\hline & 2. & Contusions & 290 & 58 \\
\hline & 3. & Lacerations & 375 & 75 \\
\hline & 4. & Incised wounds & 10 & 2 \\
\hline & & Total & 1095 & \\
\hline & & & & \\
\hline
\end{tabular}

Tabel4 show type of injuries. All type of injuries except incised wound were common.Abrasion were the commonest seen in $86 \%$, followed by laceration seen in $75 \%$ and contusion seen in $58 \%$ of all cases. Incised wound were seen in $2 \%$ cases only.

Tabel 5 Distribution of cases according to fatal injuries

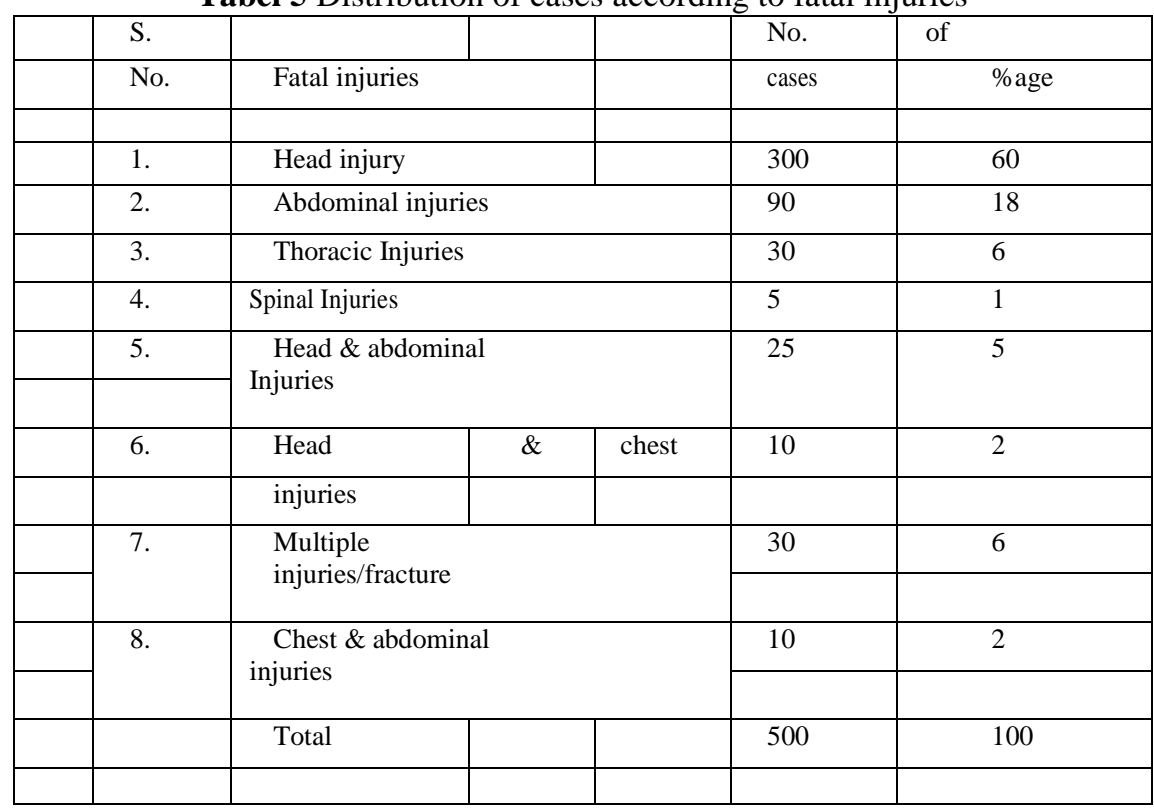

Tabel5 show fatal injuries .Out of 500 autopsy case, head injury was dominant in all deceased 300 cases followed by abdominal injuries 90 cases thoracic injuries 30cases ,multiple fracture 30 cases ,spine and neck 5 case. The combination of head and abdominal injuries 25 cases chest and abdominal injuries 10 cases while head and chest were the least accounting for death only in 2 case.This study shows that 300 death in road traffic accident were due to head injuries alone.

\section{Discussion}

Road traffic accidents (RTAs) are increasing with rapid pace and presently these are one of the leading causes of death in developing countries. Vander sluis et.al has reported that traffic is the most important cause of severe injuries and three quarters of severely injured cases who died during hospitalization are victims of traffic accidents. In the present study, a total of 500 cases of fatal road traffic accidents (RTA) have been studied in respect to distribution, nature and type of injuries. The actual time of occurrence of the accident has not been recorded in most of the fatal RTA's hence no comment on the time of occurrence of accident in the present study. A majority of fatal RTA have sustained multiple injuries. EKe $\mathrm{N}$ et. al., have also reported occurrence of multiple injuries in $93.5 \%$ of the victims.

The commonest injuries were observed on head and face in 85 percent, lower limbs 65 percent upper limbs 54 percent, chest 48 percent followed by 36 percent on abdomen and only one percent having spinal injuries. Chandra et al observed injuries on head \& face in 77.99 percent. Tripude et al ] observed 67.5 percent injuries were on head and face and 47.5percent injuries were on chest, 26.25 percent injuries were on abdomen. Singh $\mathrm{H}$ et al observed injuries on Head and face 77.6 percent, chest 44 percent, abdomen 31.8percenf, upper limbs 35.6percent, lower limbs 44.2percent, spine 12.9percent which are almost similar with present studies Menon A et al showed 88.88percent skull fractures as cause of deaths occurring in fatal accidents. Arvind $\mathrm{K}$ et 
al observedinjuries on head and face as 68.79percent, chest 26.9percen and abdomen 47.31 percent.

Multiple injuries and multiple body parts were found involved in all the cases in the present study. The injuries sustained were abrasions, contusions, lacerations, incised wounds, fractures and injuries involving internal organ. All types of injuries were common in road accidents victims. Abrasions, lacerations and contusions were more common. Abrasions were seen in 86 percent cases followed by lacerations in 75 percent cases and contusions in 58percent cases. The injuries were as a result of heavy blunt forces seen in hit and run cases, crush injuries due to impact of the vehicle and rough surface of roads. Singh $\mathrm{H}$ et al observed that fracture dislocation and lacerations were seen in 89.1 percent and 88.8percent cases respectively followed by abrasions 84.4percent. Dos Santos AM et al showed that 69.3percent of victims suffered lacerations, 51.4 percent got fractures, and 20.7percent suffered from head trauma. Abrasions constituted largest percentage (86 percent) of all injuries amongst motor bikes as victim was dragged on the road in the roadside accidents. There were total of 289 injuries in 100 cases (injuries per case being 2.9). Head injuries were the dominant cause of death among all road users cases (57percent), followed by abdominal injuries 19 percent cases, thoracic injuries 7 percent cases and multiple fractures were seen in 6percent cases. Least accounting for death 1 percent of cases was seen in spinal injuries. The present study is in concurrence with Chandra et al who observed 49.46percent of cases died of head injuries, 22.52percent of abdominal injuries, and 28 percent of multiple injuries. Singh $\mathrm{H}$ et al observed 50.4percent of cases died due to head injury followed by 19.3percent of multiple injuries, 5.3 percent of abdominal injuries and 4.2percent of chest injuries Chaudhary et al observed 56.25percent of cases died of head injuries. Arvind $\mathrm{K}$ et al observed that 31.51 percent of cases died of head injuries and 37.21 percent had head injury along with chest injury or abdominal injuries.

\section{Conclusion}

Total of 500 victims of fatal RTA were studied. The whole data was analyzed for pattern and distribution of injuries. Males constituted a large number of the victims of the carnage. Most of the victims were either illiterate or had education only up to schools level. Four or more wheelers, heavy vehicles, were involved in maximum number of accidents. Majority of the victims sustained fracture followed by laceration, abrasion, and contusion. Primary impact injuries and secondary injuries were noted mostly in lower extremities, whereas secondary impact injuries in head and neck. More than one-fourth of the deaths were due to involvement of pelvis and extremities injuries.

It may be concluded that there is urgent need to address the epidemic carnage on the roads. Road traffic deaths are to a great extent preventable. Traffic safety education should be given in schools for production of skilled and responsible drivers/road users in future. Moreover, the recommendations from the world report on road traffic injury prevention should be considered and promptly implemented. The single most important thing a person can do to stay healthy and alive is to pay close attention to the way he or she walks.

\section{Reference}

[1]. Chandra J, Dogra TD and Dikshit PC. Pattern of cranio intracranial injuries in fatal vehicular accidents in Delhi 1966-76. medSci Law 1979; 19(3): 186-94.

[2]. Tirpude BH, Naik RS, Anjankar AJ and Khajuria BK. A study of pattern of cranio-cerebral injuries in road traffic accidents. JIAFM 1998; 20(1):9-12.

[3]. Singh H and Dhatterwal SK. Pattern and distribution of injuries in fatal road traffic accidents in Rohtak (Haryana). JIAFM 2004; 26(1): 20-23.

[4]. Van der Sluis CK, Geertzen JHB, Werkcman HA and DuisHJT : Epidemiological data from severely injured patients : a retrospective study over the period 1985-1989. NederlandsTijdschriftvoorGeneeskunde 1994; $138: 2285$.

[5]. EKe N, Etebu En and Nwosu SO. Road traffic accident mortalities in Port Harcourt. Nigeria. Anil Agarwal's Internet J Foren Med Toxicol 2000; $1: 1-5$.

[6]. Singh Harnam and Dhattarwal SK. Pattern and distribution of injuries in fatal road traffic accidents in Rohtak (Haryana) 2004; 26 : 20-23.

[7]. Kochar A, sharma GK, AtulMurari and Rehan HS. Road Traffic accidents and alcohol : A prospective study. Int J Med Toxicol Legal Med. 2002, $5: 22-24$.

[8]. Gerberich SG, Robertson C.S., Gibson RW and RenierCBS : An epidemiological study of roadway fatalities related to farm vehicles. J. Occupational \& Environmental Medicine 1996; 38 : 1135-40 